\title{
State-Dependent Modulation of Breathing in Urethane-Anesthetized Rats
}

\author{
Silvia Pagliardini, ${ }^{1,3,4}$ John J. Greer, ${ }^{1,3,4}$ Gregory D. Funk, ${ }^{1,3,4}$ and Clayton T. Dickson ${ }^{1,2,3}$ \\ Departments of ${ }^{1}$ Physiology and ${ }^{2}$ Psychology, ${ }^{3}$ Centre for Neuroscience, and ${ }^{4}$ Women and Children's Health Research Institute, University of Alberta, \\ Edmonton, Alberta T6G 2E1, Canada
}

Respiratory activity is most fragile during sleep, in particular during paradoxical [or rapid eye movement (REM)] sleep and sleep state transitions. Rats are commonly used to study respiratory neuromodulation, but rodent sleep is characterized by a highly fragmented sleep pattern, thus making it very challenging to examine different sleep states and potential pharmacological manipulations within them. Sleep-like brain-state alternations occur in rats under urethane anesthesia and may be an effective and efficient model for sleep itself. The present study assessed state-dependent changes in breathing and respiratory muscle modulation under urethane anesthesia to determine their similarity to those occurring during natural sleep. Rats were anesthetized with urethane and respiratory airflow, as well as electromyographic activity in respiratory muscles were recorded in combination with local field potentials in neocortex and hippocampus to determine how breathing pattern and muscle activity are modulated with brain state. Measurements were made in normoxic, hypoxic, and hypercapnic conditions. Results were compared with recordings made from rats during natural sleep. Brain-state alternations under urethane anesthesia were closely correlated with changes in breathing rate and variability and with modulation of respiratory muscle tone. These changes closely mimicked those observed in natural sleep. Of great interest was that, during both REM and REM-like states, genioglossus muscle activity was strongly depressed and abdominal muscle activity showed potent expiratory modulation. We demonstrate that, in urethane-anesthetized rats, respiratory airflow and muscle activity are closely correlated with brain-state transitions and parallel those shown in natural sleep, providing a useful model to systematically study sleep-related changes in respiratory control.

\section{Introduction}

Breathing is an automatic process that is highly influenced by brain state. Abnormalities occur more frequently during sleep when chemosensitive and propriosensory feedback and neuromodulatory inputs are often insufficient to maintain respiratory drive to motoneurons and muscles (Aserinsky, 1965; Douglas, 2005; Horner, 2008a).

Sleep is characterized by the alternation between two main states, rapid eye movement (REM) and non-REM (nREM) sleep (Aserinsky and Kleitman, 1953; Aserinsky, 1965; Horner, 2008a). The main muscle generating respiratory airflow [the diaphragm (DIA)] shows only weak state-dependent modulation (Parmeggiani, 1978; Sieck et al., 1984). In contrast, respiratory activity in muscles, such as the genioglossus $(\mathrm{GG})$, which is important in maintaining airway patency, is reduced during nREM and declines dramatically in REM sleep (Sauerland and Harper, 1976; Remmers et al., 1978;

Received Feb. 27, 2012; revised June 26, 2012; accepted July 2, 2012.

Author contributions: S.P., J.J.G., G.D.F., and C.T.D. designed research; S.P. performed research; S.P. analyzed data; S.P., J.J.G., G.D.F., and C.T.D. wrote the paper.

This work was supported by a Natural Sciences and Engineering Research Council of Canada grant (C.T.D.) and a Canadian Institutes of Health Research grant (J.J.G.). S.P. is funded by a Parker B. Francis Foundation fellowship.

J.J.G., G.D.F., and C.T.D. are Alberta Innovates funded investigators. We thank Dr. F. Colbourne (University of Alberta, Edmonton, Alberta, (anada) for assistance with blood pressure measurements.

Correspondence should be addressed to Silvia Pagliardini, 3-020 Katz Building, University of Alberta, Edmonton, AB T6G 2E1, Canada. E-mail: silviap@ualberta.ca.

DOI:10.1523/JNEUROSCI.0948-12.2012

Copyright $\odot 2012$ the authors $\quad 0270-6474 / 12 / 3211259-12 \$ 15.00 / 0$
Horner, 2008a). This state dependence reflects that excitatory neuromodulatory inputs to respiratory networks and motoneurons decrease progressively with transitions from wakefulness to nREM and REM sleep. REM sleep-specific, glycinergic mechanisms also contribute to reduction in motoneuronal activity (Morales et al., 1987; Soja et al., 1987; Chase and Morales, 2005; Horner, 2008a; Krenzer et al., 2011). Moreover, chemosensitivity is also reduced during sleep (Douglas, 2005; Krieger, 2005; Krimsky and Leiter, 2005). Consequently, respiration during sleep becomes increasingly irregular and sleep-disordered breathing may occur.

Human sleep typically exhibits a stereotyped cycle of events with phase transitions predictably progressing from wakefulness, stages I-IV of nREM, followed by REM sleep (Carskadon and Dement, 2005). Even with this predictable sequence, sleep studies are challenging because the timing of transitions and time spent in each phase are unpredictable. This challenge is especially problematic in rodents that have highly fragmented sleep patterns. Their sleep cycle is brief (12-15 min; Zepelin et al., 2005), transitions occur frequently, and the time spent in any given state (especially REM) can be very short (seconds). Studies of REM epochs and physiological processes operating within epochs are therefore extremely challenging. Hence, there is a need for model systems that facilitate mechanistic analyses at synaptic, cellular, and network levels. Although models exist for unitary sleep-like states, they are limited by the difficulty of evoking multiple, reproducible state transitions (George et al., 1964; Tojima et al., 1992; Horner and Kubin, 1999). 
Here we explore the potential of urethane anesthesia as a sleep model to study state-dependent changes in respiratory control. We show in urethane-anesthetized rats that breathing rate, respiratory variability, sigh rate, and respiratory muscle activity are correlated to changes in brain activity and that these correlations replicate statedependent changes occurring in natural sleep. Respiratory responses to hypoxia and hypercapnia are also state dependent. In addition, analysis of urethane-anesthetized rats revealed a previously undocumented increase in abdominal expiratory activity specific to REMlike sleep that was identified during natural REM sleep.

Based on the remarkable similarity of physiological changes in natural sleep and the urethane anesthesia, and the regular, predictable nature of REM-nREM transitions in urethane-anesthetized rats, we posit that the urethane-anesthetized rat represents a simple, robustly replicable model for the mechanistic analysis of the full spectrum of events occurring during natural sleep.

\section{Materials and Methods}

Animal handling and experimental protocols were approved by the Biosciences Animal Policy and Welfare Committee of the University of Alberta according to the guidelines established by the Canadian Council on Animal Care.

Acute (urethane-anesthetized) rat preparation. Twenty-three adult male Sprague Dawley rats (250-350 g; mean, $315 \pm 10 \mathrm{~g}$ ) were used for acute experiments. Rats were initially anesthetized in halothane $3 \%$ in $100 \% \mathrm{O}_{2}$ ) while the femoral vein was cannulated, and urethane (1.5-1.9 $\mathrm{g} / \mathrm{kg}$ body weight) was gradually delivered intravenously to induce anesthesia. Additional doses of anesthesia were delivered as necessary to maintain a surgical plane of anesthesia. The trachea was cannulated, and respiratory airflow was measured with a pneumotachograph (GM Instruments) connected to a low-pressure transducer (model \#DP103-10; Valydine). In some cases, a two-way non-rebreathing valve (Hans Rudolf) was connected to the tracheal tube, and end-expiratory gases were analyzed by a gas analyzer (model \#ML206; AD Instruments) connected to a PowerLab $16 / 30$ acquisition system (AD Instruments). In four additional experiments, the femoral artery was isolated and cannulated to record mean arterial blood pressure by means of a pressure transducer (BP-1; World Precision Instruments) connected to the data acquisition system.

Bipolar EMG wire electrodes made with multi-strand, Teflon-coated, stainless steel wires (CoonerWire) were inserted into the GG, oblique abdominal (ABD), and DIA muscles and occasionally also into the levator labii superioris (LL) and intercostal (INT) muscles. Body temperature was kept constant at $37 \pm 1^{\circ} \mathrm{C}$ with a servo-controlled heating pad and a rectal probe (TR-100; Fine Science Tools).

Rats were then positioned on a stereotaxic frame, and Teflon-coated stainless steel wires (A-M Systems) were implanted in the neocortex (nCTX) and hippocampal formation (HPC) according to the following coordinates relative to bregma: nCTX: anteroposterior (AP), $+2.5 \mathrm{~mm}$; mediolateral (ML), $-1.2 \mathrm{~mm}$; dorsoventral (DV), -1.5 to $-2.0 \mathrm{~mm}$; HPC: AP, $-3.3 \mathrm{~mm}$; ML, $-2.4 \mathrm{~mm}$; DV, -2.5 to $-3.0 \mathrm{~mm}$. For nCTX recordings, the electrodes were lowered in the DV axis just below the position at which a marked increase in multiunit discharge was detected via an audio amplifier (model 3300; A-M Systems) connected to the acquisition system. This corresponds to the region just below layer $\mathrm{V}$ in the nCTX. Similarly, HPC electrodes were lowered below the position of a second (and often louder) audible multiunit discharge, corresponding to the distal apical dendritic layer of pyramidal cells in CA1. Electrodes were then fixed to the skull by jeweler's screws and dental acrylic.

Rats were allowed to stabilize for at least $1 \mathrm{~h}$ before recordings took place. Field potential activity from nCTX and HPC was amplified at $1000 \times$ gain and filtered between 0.1 and $500 \mathrm{~Hz}$, whereas EMG signals were amplified at 10,000 $\times$ and filtered between 100 and $500 \mathrm{~Hz}$. Signals were amplified and filtered using a differential AC amplifier (model 1700; A-M Systems), and activity was sampled at $1 \mathrm{kHz}$ using a PowerLab $16 / 30$ data acquisition system (AD Instruments).

Rats were allowed to spontaneously breath air (from either the environment or a medical-grade air tank) or challenged with either $5 \% \mathrm{CO}_{2}$ in air (hypercapnia) or $13.3 \% \mathrm{O}_{2}$ (mild hypoxia) for a period of $30-45$ $\min$.

Chronic (and freely behaving) rat preparation. To compare responses observed under urethane anesthesia with those occurring during natural sleep, we implanted seven male Sprague Dawley rats (200-250 g) with EEG and EMG electrodes and recorded activity in freely behaving conditions. These rats were anesthetized with ketamine $(90 \mathrm{mg} / \mathrm{kg})$ and $x y-$ lazine $(10 \mathrm{mg} / \mathrm{kg})$. During the surgery, bipolar Teflon-coated stainless steel EMG electrodes were implanted into the DIA, GG, ABD, and neck muscles. Wires were tunneled under the skin and attached to an electrical socket (Ginder Scientific). The socket was then implanted between the shoulder blades. In addition, nCTX and HPC bipolar electrodes were implanted using coordinates described above for acute experiments. Two screws were cemented to the skull to maintain the electrodes in position. The wires were then tunneled under the skin and attached to a second electrical socket positioned on the rats' neck.

Rats were given an analgesic for $2 \mathrm{~d}$ after surgery (Metacam, $2 \mathrm{mg} / \mathrm{kg}$ ) with food and water available ad libitum and maintained on a $12 \mathrm{~h}$ dark/ light cycle. During the first week after surgery, rats were habituated to the recording chamber for at least three 8-h sessions.

Recording sessions started $7 \mathrm{~d}$ after surgery. Rats were connected to tethering cables in the morning (10:00 A.M.), and data were collected between 12:00 P.M. and 5:00 P.M. Sleep analysis was performed on 2-3 h periods between 2:00 P.M. and 5:00 P.M., when rats showed consistent and robust sleep behavior.

Data analysis. During urethane anesthesia, REM-like and nREM-like states were identified by dividing the data into $6 \mathrm{~s}$ epochs, and, via spectral analysis, the percentage of total power at specific frequencies was calculated. The brain state was defined as REM-like when the power in the HPC recordings at the $3-4 \mathrm{~Hz}$ interval was $\geq 40 \%$ of total power for three consecutive $6 \mathrm{~s}$ intervals. The brain state was defined as nREM-like when the power in the nCTX recordings at the $0.5-1.5 \mathrm{~Hz}$ interval was $\geq 40 \%$ of total power for three consecutive $6 \mathrm{~s}$ intervals. Periods that did not meet these two conditions (when power in the 3-4 Hz and 0.5-1.5 $\mathrm{Hz}$ bandwidths was $<40 \%$ of HPC and nCTX total power, respectively) were identified as transition states. Transition states have also been characterized during both urethane anesthesia and natural sleep as demonstrating transient $(<0.5 \mathrm{~s}$ in duration) neocortical oscillatory $(7-15 \mathrm{~Hz})$ spindle events, consistent with activity during stage II nREM sleep in humans (Clement et al., 2008).

Tidal volume for each inspiratory cycle was calculated from the integral of the positive (inspiratory) airflow trace based on a calibration procedure in which known volumes of air were pumped sinusoidally across the pneumotach. Respiratory period was calculated with PowerLab Pro software (AD Instruments) by measuring the time between two consecutive peak inspiratory events. Respiratory muscle EMG activity was rectified and integrated ( $0.08 \mathrm{~s}$ time constant decay), and peak amplitude was calculated by LabChart7 Pro software.

Sighs were identified by the presence of an augmented respiratory effort ( $>50 \%$ increase in tidal volume or integrated DIA $_{\text {EMG }}$ peak amplitude compared with a regular breath), followed by a short post-sigh pause (Bartlett, 1971; Marshall and Metcalfe, 1988; Orem and Trotter, 1993; Hoch et al., 1998).

In control conditions, and under hypoxia or hypercapnia, four full REM-nREM state transitions were used for averaging values of airflow, frequency, $V_{\mathrm{T}}, V_{\mathrm{E}}$, and respiratory muscle peak EMG activity. Single values were averaged according to the state, and statistical analyses (onetail and two-tail dependent $t$ tests) were used to determine significance across experiments. Data values are reported as mean \pm SEM (with $t$ values, degrees of freedom, and $p$ values for each measurement). Respiratory rate variability was assessed by calculating the coefficient of variation (CV) (mean divided by SD).

\section{Results}

Sleep-like state alternations correlate with changes in respiration in urethane-anesthetized rats

Spontaneous sleep-like brain-state alternations occur in urethaneanesthetized rats (Grahn and Heller, 1989; Hunter and Milsom, 
1998; Hunter et al., 1998; Murakami et al., 2005; Clement et al., 2008). We initially determined the effects of sleep-like state alternations on respiratory activity of spontaneously breathing, urethaneanesthetized rats. As documented previously (Clement et al., 2008), field potential recordings from the nCTX and HPC showed spontaneous cyclic transitions between a deactivated pattern consisting of high-amplitude, slow-frequency $(\sim 1 \mathrm{~Hz})$ activity at both nCTX and HPC sites (nREM-like state; $3.5 \pm 0.3 \mathrm{~min} ; n=23$ ) and an activated pattern consisting of low-power, high-frequency cortical activity concomitant with high-amplitude theta frequency $(3-4 \mathrm{~Hz})$ activity in the HPC (REM-like state, $4.5 \pm 0.5 \mathrm{~min} ; n=23$ ). Occurring between these two opposing and mutually exclusive states were transitional periods. These were characterized by a more irregular activity pattern at both sites that showed spectral characteristics intermediate between activated and deactivated patterns, as well as transient spindles (short $0.5 \mathrm{~s}$ bursts of $7-15 \mathrm{~Hz}$ activity) in nCTX activity, previously associated with stage II nREM sleep in humans (Clement et al., 2008).

The transitional period was longer during REM-like to nREM-like transitions $(3.9 \pm 0.6 \mathrm{~min} ; n=23)$ than nREM-like to REM-like transitions ( $<20 s ; n=23$ ) (Fig. 1). The average period of the complete brain-state cycle was $12.1 \pm 1.0 \mathrm{~min}(n=23)$. Consistent with previous results, state alternations were not associated with variations in overt behavioral measures of the anesthetic plane and were a consistent feature in all recordings, even at high doses of urethane $(1.73 \pm 0.33 \mathrm{mg} / \mathrm{kg}$ ) (Wolansky et al., 2006; Clement et al., 2008).

Respiratory parameters were evaluated for four successive state alternations and compared across brain states (Fig. 1). Similar to natural sleep in humans (Aserinsky and Kleitman, 1953; Aserinsky, 1965) and rats (Fraigne and Orem, 2011), we confirmed initial observations (Wolansky et al., 2006; Clement et al., 2008) that respiratory period was shorter and respiratory rate variability greater during REM-like (period, $0.40 \pm 0.01 \mathrm{~s} ; \mathrm{CV}, 0.12 \pm 0.01$ ) and transition (period, $0.42 \pm 0.02 \mathrm{~s} ; \mathrm{CV}, 0.13 \pm 0.01$ ) states compared with the nREM-like state (period, $0.45 \pm 0.01 \mathrm{~s} ; \mathrm{CV}, 0.08 \pm 0.01 ; n=23$ ). Overall, we observed a $12.8 \pm 1.7 \%$ increase in the respiratory period during REM-like compared with nREM-like states $\left(t_{(22)}=7.18 ; p=\right.$ $3.3 \times 10^{-7}$ ) and a $40 \pm 16 \%$ increase in CV in REM-like compared with nREM-like states $\left(t_{(22)}=2.58 ; p=0.02\right)$.

In urethane-anesthetized rats, the occurrence of sighs (augmented breaths) was most frequent during REM-like (41.4 \pm 5.7 sighs/h) and transition ( $41.5 \pm 5.1$ sighs/h) states compared with the nREM-like state (12.4 \pm 3.2 sighs/h). These differences were significant when comparing REM-like with nREM-like states $\left(t_{(17)}=5.03\right.$, $\left.p=1.0 \times 10^{-4}\right)$ and transition to nREM states $\left(t_{(17)}=6.6, p=\right.$ $\left.4.5 \times 10^{-6} ; n=18\right)$. In nREM-like states, if present, sighs were confined to the last seconds before the transition to REM-like state. These results are also in agreement with the greater number of sighs during REM compared with nREM sleep in humans (McNamara et al., 2002; Fukumizu and Kohyama, 2004; Qureshi et al., 2009).

Tidal volume was also higher in nREM-like $(1.90 \pm 0.09$ $\mathrm{ml})$ compared with transition states $(1.85 \pm 0.09 \mathrm{ml})$ and REM states $(1.86 \pm 0.09 \mathrm{ml}, n=15)$. These differences were significant when comparing REM-like $\left(t_{(14)}=2.23, p=0.04\right)$ and transition $\left(t_{(14)}=2.26, p=0.04\right)$ states to nREM-like states. Consequently, minute ventilation was significantly increased by $8.6 \pm 5.3 \%$ in REM-like $\left(t_{(14)}=8.19, p=1.7 \times\right.$ $\left.10^{-6}\right)$ and by $5.8 \pm 5.6 \%$ in transition $\left(t_{(14)}=4.49, p=6.1 \times\right.$ $\left.10^{-4}\right)$ states compared with nREM-like states $(n=15)$.

In four rats, analysis of end-expiratory $\mathrm{CO}_{2}$ across brain states did not reveal differences in expired $\mathrm{CO}_{2}$ values across states $(5.02 \pm 0.4 \%$ in REM-like, $5.05 \pm 0.1 \%$ in transition, and $5.00 \pm 0.4 \%$ in nREM-like states), although the variability (as measured by $\mathrm{CV}$ ) of $\mathrm{CO}_{2}$ levels tended to be higher in REM-like (45.8 $\pm 25.5 \%$ increase) and transition (41.9 \pm $24.9 \%$ increase) states compared with nREM-like state, although this difference was not significant $\left(t_{(3)}=0.16, p=0.88\right.$ and $t_{(3)}=0.08, p=0.93$, respectively).

Additional experiments were performed in four rats under urethane anesthesia to evaluate blood pressure changes across brain states. Although we observed temporary drops $(\sim 5$ $\mathrm{mmHg}$ ) in blood pressure after sighs (Bartlett, 1971; Marshall and Metcalfe, 1988; Galland et al., 2000), changes in blood pressure were not significantly different in REM-like (103.4 \pm 4.9 $\mathrm{mmHg})$ and transition $(102.4 \pm 6.0 \mathrm{mmHg})$ states compared with nREM-like state $(101.7 \pm 5.4 \mathrm{mmHg})\left(t_{(3)}=0.80, p=0.48\right.$ and $t_{(3)}=0.95, p=0.41$, respectively), suggesting that mean blood pressure variations are not responsible for either brain or respiratory activity changes $(n=4)$.

\section{State-dependent modulation of respiratory muscle activity}

To describe the changes in respiratory muscle activity that underlie state-dependent changes in breathing patterns, rats were implanted with EMG electrodes in DIA $(n=13)$, INT $(n=4)$, GG $(n=19)$, LL $(n=4)$, and ABD $(n=13)$ muscles. DIA ${ }_{\mathrm{EMG}}$ and INT $_{\mathrm{EMG}}$ activity showed little state-dependent modulation (Fig. 2, Table 1), although interesting changes were observed for GG, LL, and $\mathrm{ABD}_{\mathrm{EMG}}$ activity (Figs. 2, 3).

In 14 of 19 rats tested, $\mathrm{GG}_{\mathrm{EMG}}$ inspiratory activity was strongly modulated across states: it gradually increased in amplitude at the beginning of the nREM-like state and persisted until a transition occurred. During transition and REM-like states, respiratorymodulated activity in $\mathrm{GG}_{\mathrm{EMG}}$ disappeared or was markedly decreased (Fig. 2). On average in this subset of animals $(n=14)$, there was a $25.1 \pm 21.7 \%\left(t_{(13)}=1.97, p=0.03\right)$ and $30.1 \pm$ $19.1 \%\left(t_{(13)}=1.93, p=0.04\right)$ decrease in $\int G G_{\text {EMG }}$ peak activity during REM-like and transition states, respectively, when compared with nREM-like state. Of the remaining five rats, one showed no $\mathrm{GG}_{\mathrm{EMG}}$ state-dependent modulation and four rats showed only weak inspiratory modulation across states $\left[\int G_{\mathrm{EMG}}\right.$ peak activity decreased $<4 \%$ (nonsignificantly) during REM-like compared with nREM-like states in this subset of animals; $n=5$ ]. However, the significant state-dependent modulation of $\mathrm{GG}_{\mathrm{EMG}}$ activity in the majority of our experiments in urethaneanesthetized rats is similar to that reported for naturally sleeping rats (Megirian et al., 1985; Horner, 2008a).

$\mathrm{ABD}_{\mathrm{EMG}}$ activity was recorded in 13 rats. In six rats, activity was tonic and did not change across brain states (Fig. 4, control trace). In the remaining seven rats, $\mathrm{ABD}_{\mathrm{EMG}}$ activity was modulated across states, switching from a tonic pattern during the nREM-like state to a rhythmic expiratory-related mode during REM-like and transition states (Fig. 3). The amplitude of the $\mathrm{ABD}_{\mathrm{EMG}}$ expiratory activity was not consistent throughout the REM-like periods but rose from baseline levels with a mean delay of $1.7 \pm 0.3 \mathrm{~min}$ from the beginning of the REM-like epoch until it reached a plateau. Although this activity occurred principally during the REM-like state, average measures of EMG values did not yield a significant difference across states because of its variability and delay $\left(80 \pm 62 \%\right.$ increase in REM-like, $t_{(6)}=1.78, p=$ 0.06 and $40 \pm 41 \%$ increase in transition, $t_{(6)}=2.13, p=0.04$ compared with nREM-like state; $n=7$ ). When only periods of $\mathrm{ABD}_{\mathrm{EMG}}$ activity during the plateau phase of activation were considered, activity was increased by $150 \pm 94 \%\left(t_{(6)}=1.97, p=\right.$ $0.048)$ in REM-like and $81 \pm 65 \%\left(t_{(6)}=1.86, p=0.05\right)$ in 

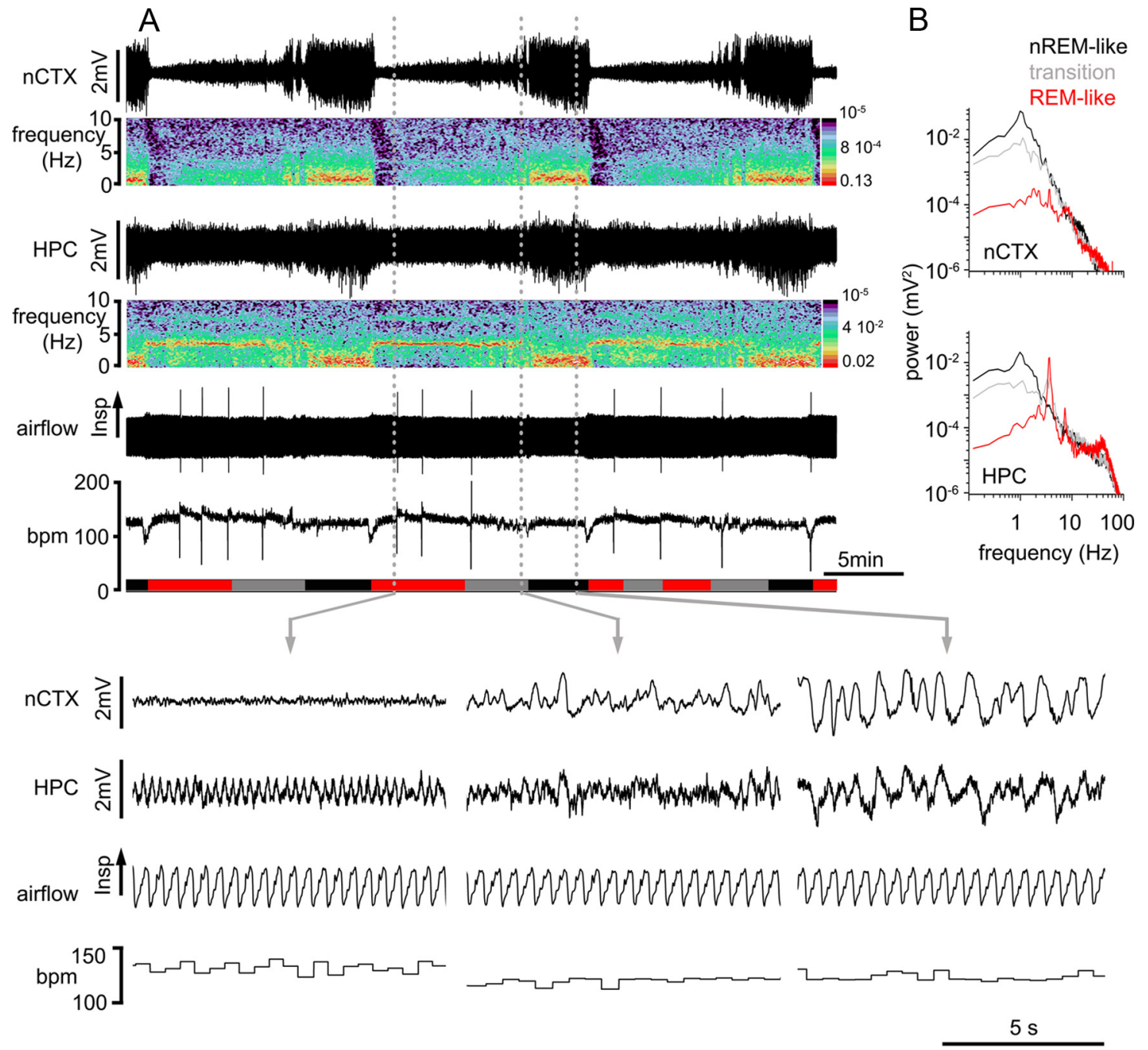

C

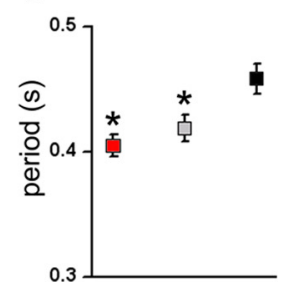

D

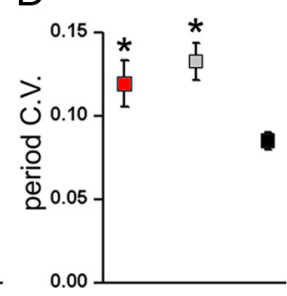

$E$

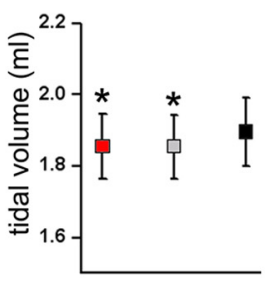

$\mathrm{F}$

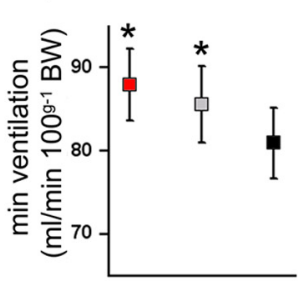

G

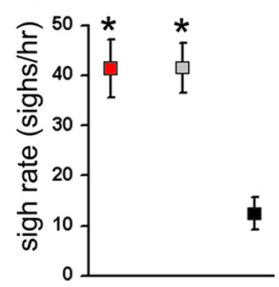

Figure 1. State-dependent modulation of breathing in urethane-anesthetized rats. A, Long-term EEG recordings at nCTX and HPC sites and corresponding power spectrograms, respiratory airflow, and breathing rate (bpm) show the rhythmic alternation of brain activity and the associated changes in respiratory flow and breathing frequency across brain states. Spectrograms indicate the prevalence of power at $\sim 1 \mathrm{~Hz}$ in both nCTX and HPC during nREM-like state and the prevalence of electrical power at $\sim 4 \mathrm{~Hz}$ in the HPC during REM-like states. The transition state is characterized by weak nCTX (1 Hz) and HPC (3-4 Hz) power. Schematic blocks at the bottom of the plot indicate time spent in REM-like (red), transition (gray), and nREM-like (black) epochs. Dashed vertical gray lines indicate the time point from which the traces displayed below are taken. Magnification of traces in REM-like (left), transition (middle), and nREM-like (right) states. $\boldsymbol{B}$, Power spectral analysis for nCTX (top) and HPC (bottom) during nREM-like, REM, and transition states further indicate the prevalence of $\sim 1 \mathrm{~Hz}$ power in nCTX and HPC during nREM-like state and the prevalence of $\sim 4 \mathrm{~Hz}$ power in HPC during REM-like events. $C-G$, Average pooled period, $(V$ of the period, tidal volume, minute ventilation, and sigh rate in REM-like (red), transition (gray), and nREM-like (black) epochs. Asterisks indicate statistical significance $(p<0.05$ ) of states (REM-like or transition) relative to nREM-like epochs. $\boldsymbol{C}, \boldsymbol{D}, n=23 ; \boldsymbol{E}, \boldsymbol{F}, n=15 ; \boldsymbol{G}, n=18$.

transition states compared with nREM states $(n=7)$. These results suggest that $\mathrm{ABD}_{\mathrm{EMG}}$ activity, although variable, does show an increase in expiratory-related activity in REM-like state.

Similarly, we recorded EMG from LL $(n=6)$, another respiratory-modulated muscle that is innervated by the buccal branch of the facial nerve. In four experiments, $\mathrm{LL}_{\mathrm{EMG}}$ showed inspiratory-related activity that increased during REM-like (48.2 \pm $\left.20.8 \%, t_{(3)}=4.6, p=0.01\right)$ and transition $\left(19.2 \pm 16.4 \%, t_{(3)}=3.64\right.$, $p=0.02)$ states compared with nREM-like states $(n=4)$.
State-dependent modulation of chemosensitivity

To test how respiratory chemosensitivity changes with brain state, we administered hypercapnic and hypoxic gas mixtures for $30-45$ min across state changes and analyzed respiration variables in relation to changes in brain state.

\section{Hypercapnia}

In eight rats, we tested the responses to $5 \% \mathrm{CO}_{2}$ in air across three to four REM-like to nREM-like cycles (Fig. 4). Brain state and 


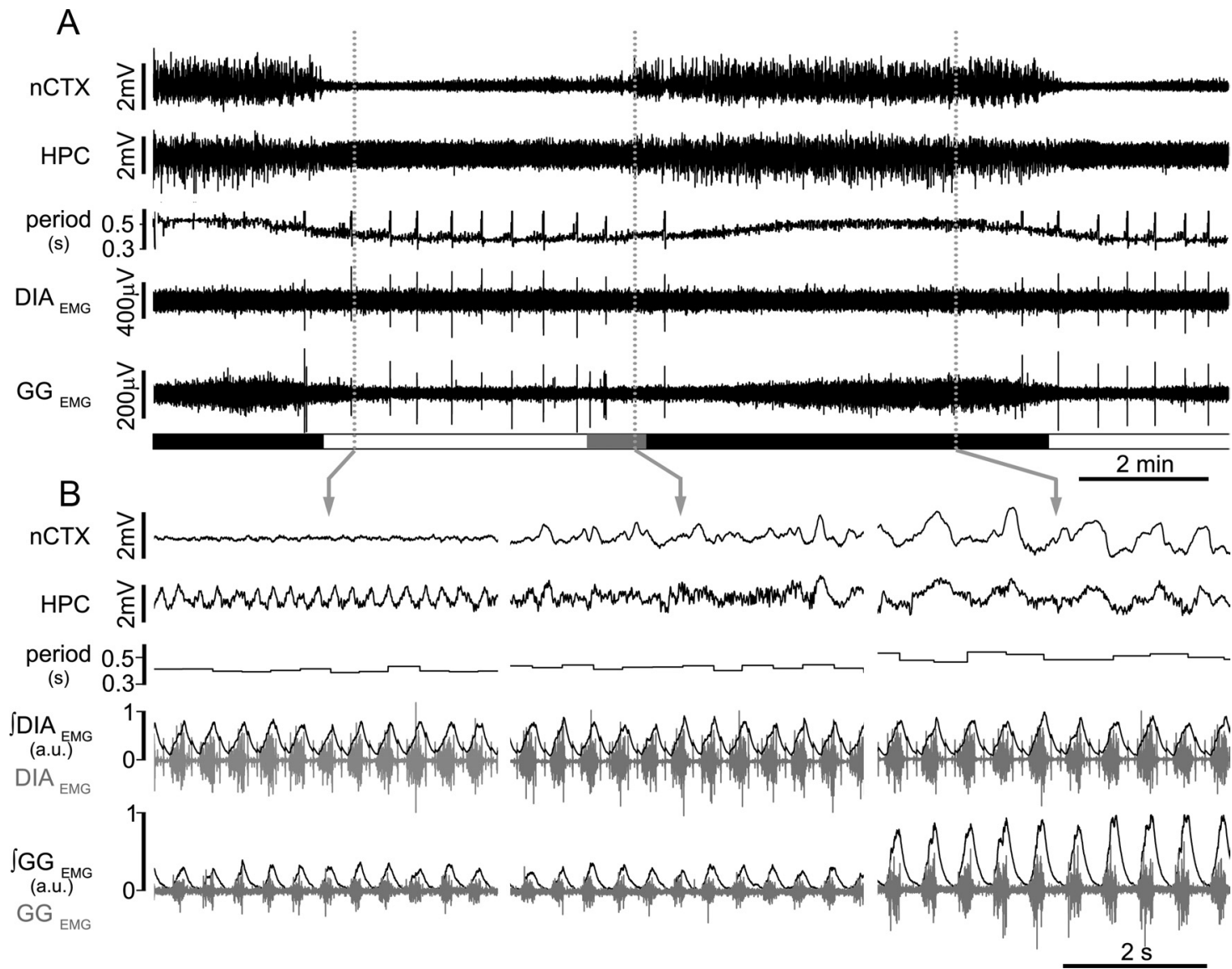

Figure 2. State-dependent modulation of GG muscle activity in urethane-anesthetized rats. $A$, Simultaneous EEG (nCTX and HPC) and EMG (DIA and GG) with ongoing respiratory period across brain-state alternations. Schematic blocks at the bottom of the plot indicate time spent in REM-like (white), transition (gray), and nREM-like (black) epochs. B, Details of EEG traces, period, raw EMG (gray), and rectified and integrated EMG traces of DIA and GG (black). Note the lack of state-dependent modulation of DIA and the strong activation of GG ${ }_{E M G}$ during nREM-like state ( $\left.n=14\right)$.

Table 1. Integrated peak EMG activity of different respiratory muscles across brainstate transitions in urethane-anesthetized rats

\begin{tabular}{|c|c|c|c|}
\hline & REM-like & Transition & nREM-like \\
\hline Peak $\int D I A_{E M G}$ & $0.99 \pm 0.23(0.56)$ & $0.97 \pm 0.22^{*}(0.007)$ & $1 \pm 0.23$ \\
\hline Peak $\int I_{N T}$ & $0.98 \pm 0.31(0.3)$ & $0.97 \pm 0.28(0.09)$ & $1 \pm 0.29$ \\
\hline Peak $\int \mathrm{GG}_{\mathrm{EMG}}$ & $0.74 \pm 0.22^{*}(0.03)$ & $0.70 \pm 0.19^{*}(0.04)$ & $1 \pm 0.31$ \\
\hline Peak $\int A B D_{\text {EMG }}$ & $\begin{array}{l}1.81 \pm 0.62(0.06) \\
2.49 \pm 0.94^{* *}(0.048)\end{array}$ & $\begin{array}{l}1.35 \pm 0.11^{*}(0.04) \\
1.81 \pm 0.64(0.05)\end{array}$ & $1 \pm 0.23$ \\
\hline Peak $\int L L_{E M G}$ & $1.48 \pm 0.21^{*}(0.01)$ & $1.19 \pm 0.2^{*}(0.02)$ & $1 \pm 0.13$ \\
\hline
\end{tabular}

Averaged integrated peak EMG values for DIA, INT, GG, ABD, and LL muscles for the REM-like, transition, and nREM-like states in urethane-anesthetized rats. Values were normalized to the averaged EMG peak value obtained during nREM-like state. Values in parentheses are $p$ values for comparison between nREM-like state and REM-like or transition states. ${ }^{*} p<0.05$, statistical significance of states (REM-like or transition) relative to $n R E M-l i k e$ epochs. ${ }^{* *} p<0.05$, statistical significance of changes during plateau period of abdominal activation in REM-like relative to nREM-like epochs.

transitions were moderately affected, in that the REM-like state was significantly reduced in duration (from $3.7 \pm 0.5$ to $2.0 \pm 0.3$ $\mathrm{min}$ ) and the percentage of HPC total power in the $3-4 \mathrm{~Hz}$ bandwidth decreased by $15.4 \pm 5.4 \%(n=8)$. Neither the duration of nREM-like epochs nor the relative nCTX power $(1 \mathrm{~Hz})$ during these states were significantly affected by hypercapnia. Brainstate alternations persisted, and the REM-like to nREM-like cycle period was slightly reduced (from $11.6 \pm 0.6$ to $10.4 \pm 0.6 \mathrm{~min}$, $\left.t_{(7)}=2.0, p=0.04\right)$.

During this manipulation, the respiratory period was not affected (Table 2), although it remained consistently lower in REM-like $(0.41 \pm 0.02 \mathrm{~s})$ and transition $(0.40 \pm 0.02 \mathrm{~s})$ states compared with the nREM-like state $(0.43 \pm 0.02 \mathrm{~s})$. Tidal volume increased significantly $(\sim 10 \%)$ in all states compared with control values (increases of $10.9 \pm 2.4,10.3 \pm 3.6$, and $11.7 \pm 3.7 \%$ in REM-like, transition, and nREM-like states, respectively, with $t$ and $p$ values of $t_{(4)}=5.2, p=3.2 \times 10^{-3} ; t_{(4)}=3.3, p=0.015$; and $t_{(4)}=3.9, p=8.7 \times 10^{-3} ; n=5$; Table 2). Increases in minute ventilation were significant only in the nREM-like state $\left(10.2 \pm 4.9 \%\right.$ increase compared with control values, $t_{(4)}=2.17$, $p=0.047$; Table 2). Under hypercapnia, sigh rate also increased, rising $36 \pm 15 \%\left(t_{(7)}=2.28, p=0.03\right)$ during REM-like, $20 \pm$ $17 \%\left(t_{(7)}=1.4, p=0.09\right)$ during transition, and $45.9 \pm 37.3 \%$ $\left(t_{(7)}=1.23, p=0.12\right)$ during nREM-like states $(n=8)$.

Respiratory muscle activity was also affected by hypercapnia. Peak $\int D I A_{\text {EMG }}$ activity increased consistently by $\sim 20 \%$ relative to control during all states (increases of $23.4 \pm 9.5,23.9 \pm 10.4$, and $21.7 \pm 7.7 \%$, respectively, for REM-like, transition, and nREM-like states with $t$ and $p$ values of $t_{(7)}=2.15, p=0.03 ; t_{(7)}=$ 1.95, $p=0.04$; and $t_{(7)}=2.4, p=0.02 ; n=8$; Table 3). Peak $\int \mathrm{GG}_{\mathrm{EMG}}$ inspiratory-related activity also increased significantly across all states (Fig. 4, Table 3 ) but maintained its characteristic state-dependent modulation. The strong inspiratory-related activity during nREM-like state increased by $84.1 \pm 21.7 \%\left(t_{(7)}=\right.$ $3.56, p=5 \times 10^{-3}$ ) compared with control. $\mathrm{GG}_{\mathrm{EMG}}$ activity during hypercapnia increased also during REM-like $\left(64.4 \pm 18.0 \%, t_{(7)}=\right.$ $3.09, p=0.009)$ and transition $\left(65.2 \pm 18.2 \%, t_{(7)}=3.09, p=9 \times\right.$ $\left.10^{-3}\right)$ states compared with control values, but this activity was still reduced by $22.4 \pm 15.8 \%\left(t_{(7)}=2.98, p=0.02\right)$ and $27.8 \pm$ $13.5 \%\left(t_{(7)}=3.43, p=0.01\right)$ in REM-like and transition, respectively, compared with the nREM-like state $(n=8)$. Similarly, 


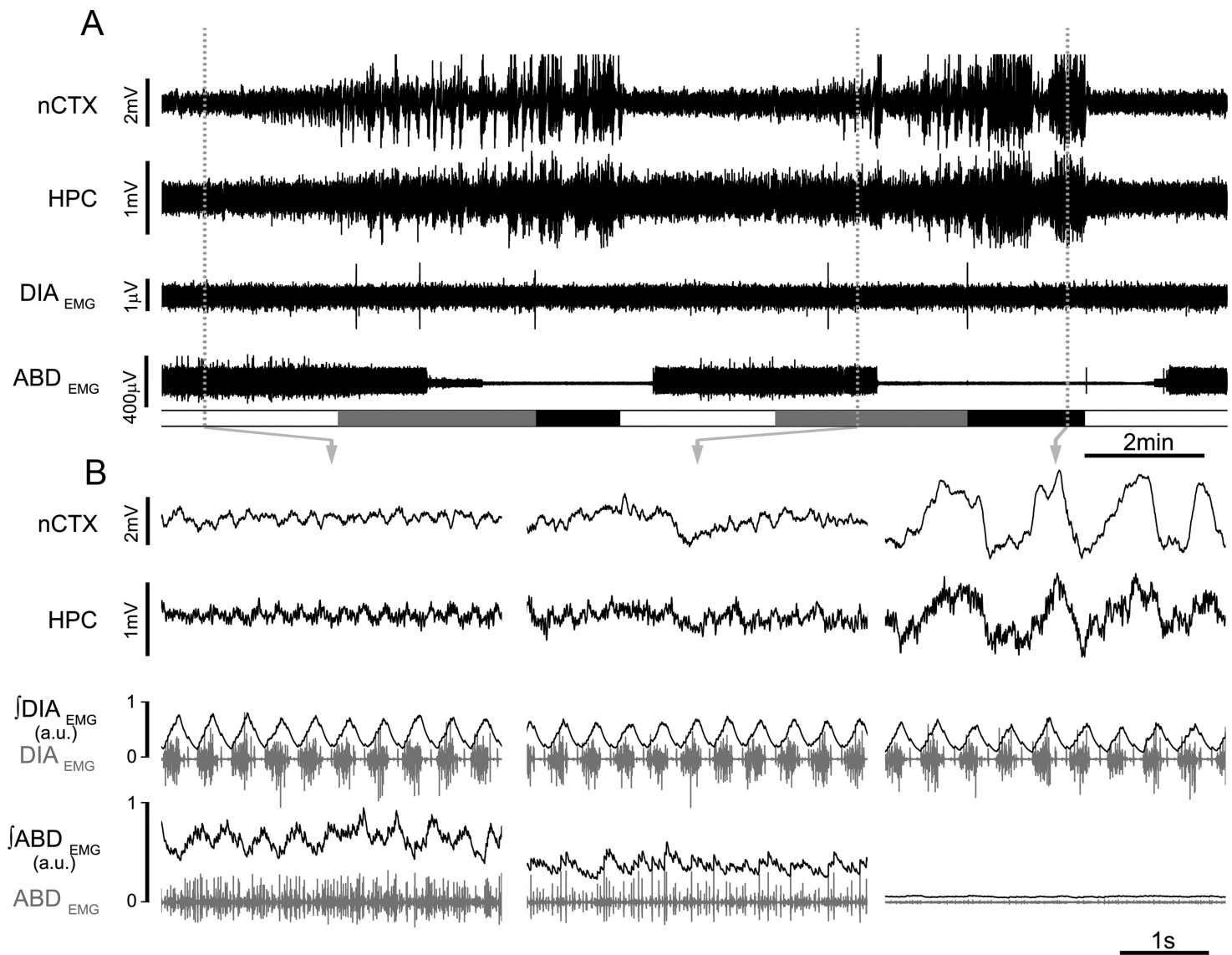

Figure 3. State-dependent modulation of abdominal muscle activity in urethane-anesthetized rats. $A$, Simultaneous EEG (nCTX and HPC) and EMG (DIA and ABD) across brain-state alternations. Schematic blocks at the bottom of the plot indicate time spent in REM-like (white), transition (gray), and nREM-like (black) epochs. $\boldsymbol{B}$, Details of EEG traces, raw EMG (gray), and rectified and integrated EMG traces of DIA and ABD (black). Note the expiratory-modulated activation of $\mathrm{ABD}_{\mathrm{EMG}}$ activity during REM-like and transition states $(n=7)$.
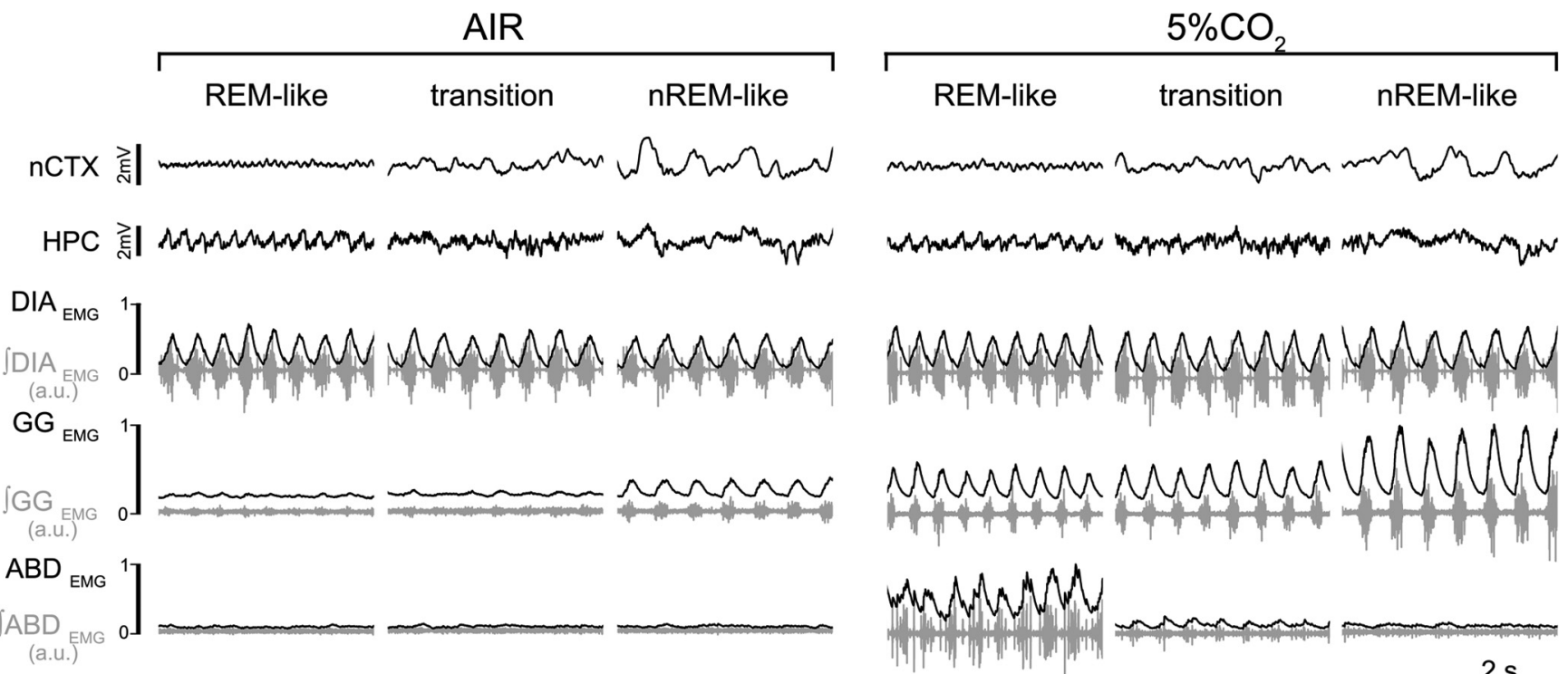
Table 2. Respiratory changes to hypercapnia $\left(5 \% \mathrm{CO}_{2}\right.$ in air) across brain-state alternations

\begin{tabular}{|c|c|c|c|c|c|c|}
\hline & \multicolumn{2}{|l|}{ REM-like } & \multicolumn{2}{|l|}{ Transition } & \multicolumn{2}{|l|}{ nREM-like } \\
\hline & AIR & $5 \% \mathrm{CO}_{2}$ & AIR & $5 \% \mathrm{CO}_{2}$ & AIR & $5 \% \mathrm{CO}_{2}$ \\
\hline Respiratory period (s) & $0.38 \pm 0.01$ & $\begin{aligned} 0.41 & \pm 0.02 \\
+5.0 & \pm 2.6 \%(0.06)\end{aligned}$ & $0.38 \pm 0.01$ & $\begin{aligned} & 0.40 \\
+ & \pm 0.02 \\
+4.8 & \pm 2.7 \%(0.06)\end{aligned}$ & $0.43 \pm 0.01$ & $\begin{aligned} 0.43 & \pm 0.02 \\
+1.0 & \pm 1.8 \%(0.28)\end{aligned}$ \\
\hline Tidal volume (ml) & $1.77 \pm 0.12$ & $\begin{aligned} 1.96 & \pm 0.12^{*} \\
+0.9 & \pm 2.4 \%\left(3.2 \times 10^{-3}\right)\end{aligned}$ & $1.77 \pm 0.11$ & $\begin{aligned} & 1.95 \pm 0.12^{*} \\
+ & 10.3 \pm 3.6 \%(0.015)\end{aligned}$ & $1.78 \pm 0.12$ & $\begin{aligned} 1.98 & \pm 0.12^{*} \\
+11.7 & \pm 3.7 \%\left(8.7 \times 10^{-3}\right)\end{aligned}$ \\
\hline Minute ventilation $(\mathrm{ml} / \mathrm{min} \times 100 \mathrm{~g})$ & $97.3 \pm 3.5$ & $\begin{array}{l}105.7 \pm 7.6 \\
+8.1 \pm 4.8 \%(0.07)\end{array}$ & $97.0 \pm 4.8$ & $\begin{array}{l}105.0 \pm 7.9 \\
+7.6 \pm 5.9 \%(0.11)\end{array}$ & $89.7 \pm 4.2$ & $\begin{aligned} 99.5 & \pm 8.0^{*} \\
+10.2 & \pm 4.9 \%(0.047)\end{aligned}$ \\
\hline Sigh rate $(s / h)$ & $46.5 \pm 9.8$ & $\begin{aligned} & 60.1 \pm 14.9^{*} \\
+ & 35.6 \pm 14.6 \%(0.03)\end{aligned}$ & $52.7 \pm 7.0$ & $\begin{aligned} 66.9 & \pm 14.7 \\
+19.8 & \pm 17.4 \%(0.09)\end{aligned}$ & $16.5 \pm 5.6$ & 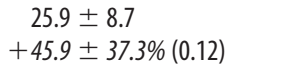 \\
\hline Peak $\int D I A_{E M G}$ (а.u.) & $0.98 \pm 0.16$ & $\begin{aligned} & 1.22 \pm 0.22 * \\
+ & 23.4 \pm 9.5 \%(0.03)\end{aligned}$ & $0.96 \pm 0.16$ & $\begin{aligned} & 1.19 \pm 0.21^{*} \\
+ & 23.9 \pm 10.4 \%(0.04)\end{aligned}$ & $1.00 \pm 0.16$ & $\begin{aligned} & 1.22 \pm 0.20^{*} \\
+ & 21.7 \pm 7.7 \%(0.02)\end{aligned}$ \\
\hline Peak $\int \mathrm{GG}_{\mathrm{EMG}}$ (a.u.) & $0.79 \pm 0.1$ & $\begin{aligned} & 1.38 \pm 0.38^{*} \\
+ & 64.4 \pm 18.0 \%(0.009)\end{aligned}$ & $0.74 \pm 0.8$ & $\begin{aligned} & 1.28 \pm 0.24^{*} \\
+65.2 & \pm 18.2 \%\left(9 \times 10^{-3}\right)\end{aligned}$ & $1.00 \pm 0.17$ & $\begin{aligned} 1.78 & \pm 0.32^{*} \\
+84.1 & \pm 21.7 \%\left(5 \times 10^{-3}\right)\end{aligned}$ \\
\hline Peak $\int A B D_{E M G}$ (a.u.) & $1.28 \pm 0.24$ & $\begin{aligned} & 2.77 \pm 1.12 \\
+ & 96.5 \pm 43.2 \%(0.09)\end{aligned}$ & $1.02 \pm 0.03$ & $\begin{aligned} 2.37 & \pm 0.40^{*} \\
+132 & \pm 36 \%(0.02)\end{aligned}$ & $1.00 \pm 0.02$ & $\begin{aligned} 2.01 & \pm 0.38^{*} \\
+103 & \pm 41 \%(0.04)\end{aligned}$ \\
\hline
\end{tabular}

Peak EMG activity is calculated based on baseline level of activity during nREM-like state in air breathing. Averaged respiratory period, tidal volume, minute ventilation, sigh rate, and integrated peak EMG activity for DIA, GG, and ABD muscles for REM-like, transition, and nREM-like states during control and hypercapnia. Values in italics indicated the percentage of change compared with control (AIR) measurements for each state, and values in parentheses indicates statistical changes significance ( $p$ value) within state (with asterisks indicating statistical significance of the relative changes).

Table 3. Respiratory changes to hypoxia $\left(13.3 \% \mathrm{O}_{2}\right.$ in air) across brain-state alternations

\begin{tabular}{|c|c|c|c|c|c|c|}
\hline & \multicolumn{2}{|l|}{ REM-like } & \multicolumn{2}{|l|}{ Transition } & \multicolumn{2}{|l|}{ nREM-like } \\
\hline & AIR & $13.3 \% \mathrm{O}_{2}$ & AIR & $13.3 \% \mathrm{O}_{2}$ & AIR & $13.3 \% \mathrm{O}_{2}$ \\
\hline Respiratory period (s) & $0.42 \pm 0.02$ & $\begin{aligned} 0.38 & \pm 0.01^{*} \\
-11.0 & \pm 2.1 \%\left(7.5 \times 10^{-4}\right)\end{aligned}$ & $0.42 \pm 0.02$ & $\begin{aligned} 0.39 & \pm 0.02^{*} \\
-8.9 & \pm 2.1 \%\left(1.7 \times 10^{-3}\right)\end{aligned}$ & $0.47 \pm 0.01$ & $\begin{aligned} & 0.42 \pm 0.02^{*} \\
-10.3 & \pm 2.7 \%\left(3.0 \times 10^{-3}\right)\end{aligned}$ \\
\hline Tidal volume (ml) & $1.81 \pm 0.16$ & $\begin{array}{l}1.79 \pm 0.14 \\
-0.3 \pm 0.3 \%(0.40)\end{array}$ & $1.79 \pm 0.167$ & 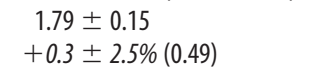 & $1.87 \pm 0.19$ & $\begin{array}{l}1.87 \pm 0.19 \\
+0.1 \pm 3.2 \%(0.49)\end{array}$ \\
\hline Minute ventilation $(\mathrm{ml} / \mathrm{min} \times 100 \mathrm{~g})$ & $75.4 \pm 9.4$ & $\begin{aligned} 82.1 & \pm 9.3^{*} \\
+9.3 & \pm 1.6 \%\left(3.5 \times 10^{-3}\right)\end{aligned}$ & $74.7 \pm 9.9$ & $\begin{array}{l}79.3 \pm 10.2^{*} \\
+6.3 \pm 2.0 \%(0.04)\end{array}$ & $70.6 \pm 9.2$ & $\begin{array}{l}78.2 \pm 9.6^{*} \\
+9.3 \pm 1.5 \%(0.002)\end{array}$ \\
\hline Sigh rate $(s / h)$ & $36.6 \pm 13.0$ & $\begin{array}{l}164.0 \pm 34.5^{*} \\
+579 \pm 212 \%\left(7.8 \times 10^{-4}\right)\end{array}$ & $42.2 \pm 13.3$ & $\begin{array}{l}145.6 \pm 26.7^{*} \\
+377 \pm 118 \%\left(4.5 \times 10^{-4}\right)\end{array}$ & $15.9 \pm 4.2$ & $\begin{aligned} & 72.5 \pm 22.7^{*} \\
+ & 431 \pm 169 \%(0.01)\end{aligned}$ \\
\hline Peak $\int D I A_{E M G}$ (а.u.) & $0.97 \pm 0.21$ & $\begin{aligned} & 1.17 \pm 0.46 \\
+ & 5.4 \pm 23.8(0.27)\end{aligned}$ & $0.93 \pm 0.2$ & $\begin{aligned} & 1.18 \pm 0.45 \\
+ & 12.6 \pm 23.0(0.23)\end{aligned}$ & $1 \pm 0.2$ & $\begin{array}{l}1.17 \pm 0.44 \\
+2.4 \pm 22.7(0.29)\end{array}$ \\
\hline Peak $\int G_{E M G}$ (a.u.) & $0.85 \pm 0.27$ & $\begin{array}{l}0.72 \pm 0.21 \\
-3.6 \pm 9.8 \%(0.25)\end{array}$ & $0.82 \pm 0.25$ & $\begin{array}{l}0.72 \pm 0.22 \\
-3.1 \pm 9.9 \%(0.3)\end{array}$ & $1 \pm 0.31$ & $\begin{aligned} 0.72 & \pm 0.22 \\
-17.0 & \pm 8.8 \%(0.07)\end{aligned}$ \\
\hline Peak $\int A B D_{E M G}$ (a.u.) & $1.23 \pm 0.21$ & $\begin{aligned} & 1.50 \pm 0.40 \\
+ & 19.9 \pm 19.5 \%(0.19)\end{aligned}$ & $1.17 \pm 0.19$ & $\begin{aligned} & 1.32 \pm 0.32 \\
+ & \pm 0.8 \pm 14.3(0.26)\end{aligned}$ & $1 \pm 0.12$ & $\begin{aligned} & 1.49 \pm 0.41 \\
+ & 43.6 \pm 29.6 \%(0.11)\end{aligned}$ \\
\hline
\end{tabular}

Peak EMG activity is calculated based on baseline level of activity during nREM-like state in air breathing. Averaged respiratory period, tidal volume, minute ventilation, sigh rate, and integrated peak EMG activity for DIA, GG, and ABD muscles for REM-like, transition, and nREM-like states during control and hypoxia. Values in italics indicated the percentage of change compared with control (AIR) measurements for each state, and values in parentheses indicates statistical changes significance ( $p$ values) within state (with asterisks indicating statistical significance of the relative changes).

\section{Hypoxia}

Under mild hypoxia ( $13.3 \% \mathrm{O}_{2}$; Fig. 5), we observed a reduction in the duration of the nREM-like state $(-32.1 \pm 10.3 \%$ compared with control) in favor of a prolonged REM-like state $(+112 \pm 57 \%)$. The effect was more dramatic at the beginning of the hypoxic episode and diminished with time. As a consequence, REM-like to nREM-like cycle duration increased from $10.5 \pm 1.1$ to $11.4 \pm 1.4 \mathrm{~min}$ in hypoxia $\left(t_{(7)}=3.91, p=0.01, n=8\right)$.

In contrast to hypercapnia, hypoxia had no significant effect on tidal volume across states $(0.3 \pm 0.3 \%$ reduction during REM-like, $t_{(3)}=0.4, p=0.4 ; 0.3 \pm 2.5 \%$ increase during transition, $t_{(3)}=0.07$, $p=0.5$; and a $0.1 \pm 3.2 \%$ increase during nREM-like, $t_{(3)}=0.06$, $p=0.5 ; n=4$ ) but did cause a significant decrease in respiratory period in all states compared with control values $(11.0 \pm 2.1 \%$ decrease in REM-like state, $t_{(7)}=5.03, p=7.5 \times 10^{-4} ; 8.9 \pm 2.1 \%$ decrease in transition state, $t_{(7)}=4.32, p=1.7 \times 10^{-3} ; 10.3 \pm$ $2.7 \%$ decrease in nREM-like state, $t_{(7)}=3.88, p=3.0 \times 10^{-3}$; $n=8$; Table 3). However, as in air breathing, respiratory period was greater (i.e., frequency was slower) in the nREM-like period $(0.42 \pm 0.02 \mathrm{~s})$ compared with other states $(0.38 \pm 0.01 \mathrm{~s}$ in REM-like and $0.39 \pm 0.02 \mathrm{~s}$ in transition states). As a consequence of the hypoxia-induced frequency increase, minute ventilation was significantly increased in all states compared with control values $\left(9.3 \pm 1.6 \%\right.$ increase in REM-like state, $t_{(3)}=6.60$, $p=3.5 \times 10^{-3} ; 6.3 \pm 2.0 \%$ increase in transition states, $t_{(3)}=$ 2.63, $p=0.04 ; 9.3 \pm 1.5 \%$ increase in nREM-like state, $t_{(3)}=$ 7.88, $p=0.002 ; n=4$; Table 3).

Changes in peak $\int \mathrm{DIA}_{\mathrm{EMG}}$ activity were limited in response to hypoxia $\left(5.4 \pm 23.8 \%\right.$ increase in REM-like, $t_{(5)}=0.64, p=$ $0.27 ; 12.6 \pm 23.0 \%$ increase in transition, $t_{(5)}=0.80, p=0.23$; $2.4 \pm 22.7 \%$ increase in nREM-like state, $t_{(5)}=0.58, p=0.29$; $n=6$; Fig. 5, Table 3). However, peak $\int \mathrm{GG}_{\mathrm{EMG}}$ inspiratory activity lost its state dependency during hypoxia (i.e., the nREMspecific inspiratory modulation was absent) but showed no significant changes in amplitude with hypoxia (3.6 $\pm 9.8 \%$ decrease in REM-like states, $t_{(7)}=0.71, p=0.25 ; 3.1 \pm 9.9 \%$ decrease in transition states, $t_{(7)}=0.55, p=0.3 ; 17.0 \pm 8.8 \%$ decrease in nREM-like states, $t_{(7)}=1.63, p=0.07 ; n=8$; Fig. 5, Table 3 ). Hypoxia was more powerful in generating sighs than hypercapnia $(579 \pm 212 \%$ increase in sigh rate in REM-like states compared with control, $t_{(7)}=5.00, p=7.8 \times 10^{-4} ; 377 \pm 118 \%$ increase in transition states, $t_{(7)}=5.5, p=4.5 \times 10^{-4} ; 431 \pm 169 \%$ increase in nREM-like states, $t_{(7)}=2.78, p=0.01 ; n=8$; Table 3 ). These results suggest that, under urethane anesthesia, a mild hypoxic stimulus across states affects minute ventilation by reducing re- 

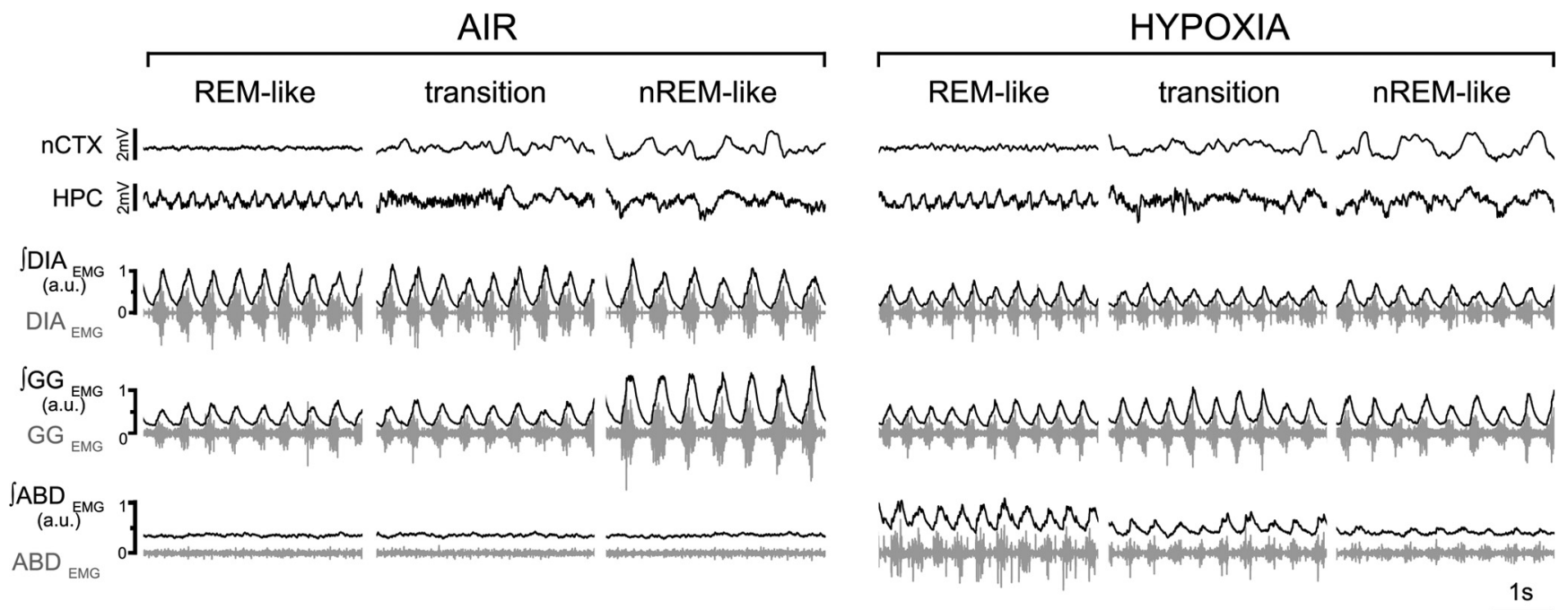

Figure 5. Hypoxic response across brain states. EEG ( $n C T X$ and HPC) and EMG (DIA, GG, and ABD. raw traces in gray; rectified and integrated EMG traces in black) in control (left) and during hypoxia $\left(13.3 \% 0_{2}\right.$; right) in REM-like, transition, and nREM-like epochs. Note the state-dependent potentiation of $\mathrm{ABD}_{\mathrm{EMG}_{\mathrm{G}}}$ activity and the lack of state-dependent modulation of $\mathrm{GG}_{\mathrm{EMG}}$ during $\mathrm{nREM}$-like epochs under hypoxia $(n=8)$.

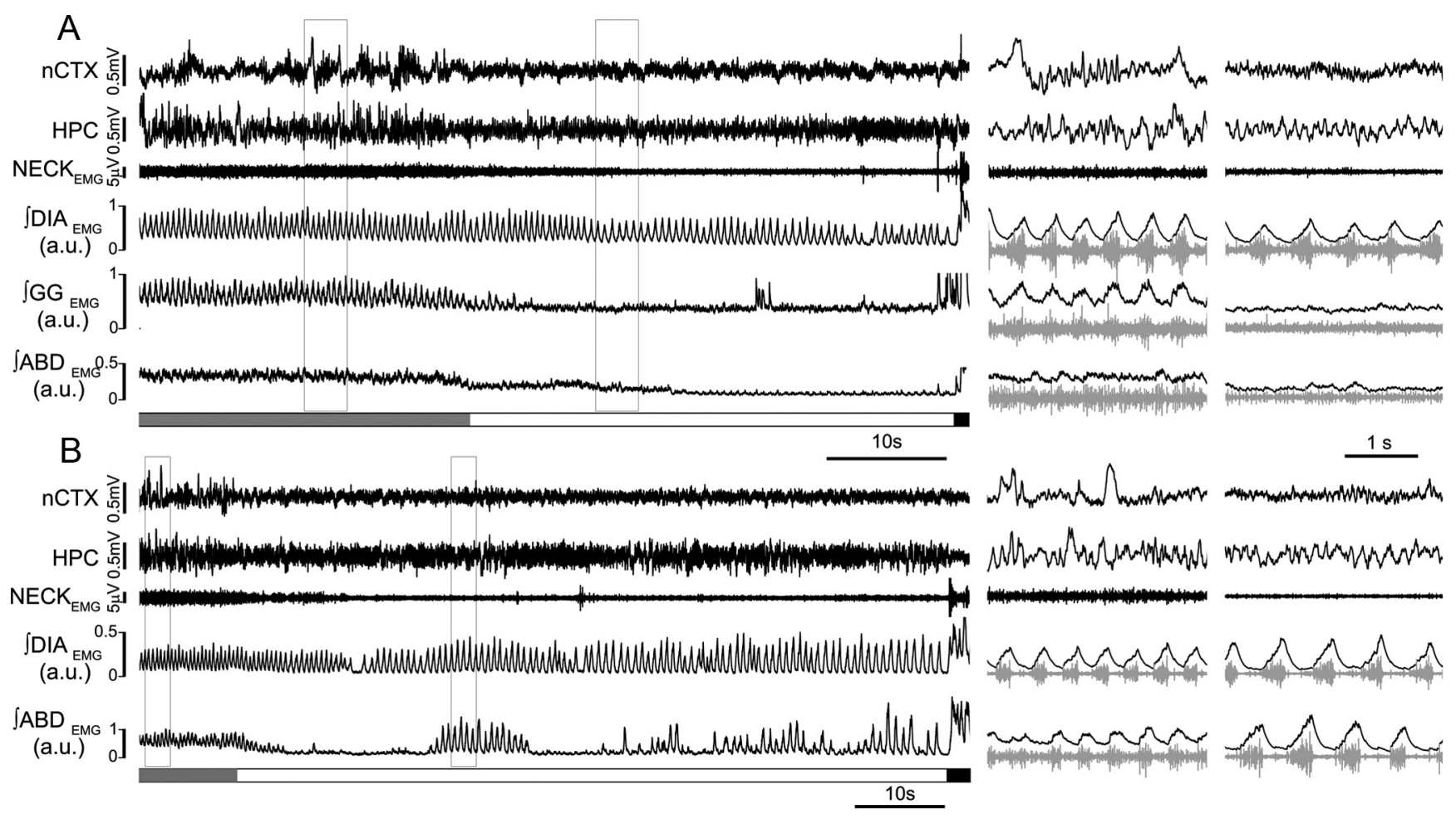

Figure 6. State-dependent modulation of breathing in natural sleep. $A$, EEG ( $(n C T X$ and $H P C$ ) and EMG (raw neck, and rectified and integrated traces of DIA, GG, and ABD) activity during transition

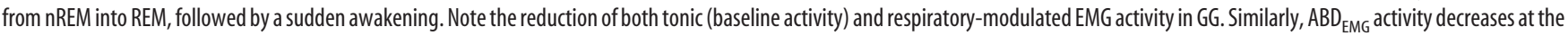
beginning of the REM epoch. Details of nREM and REM epochs (boxes on long trace recordings) are shown on the right of the panel. $\boldsymbol{B}$, Long trace and details from a different nREM-REM-wake epoch recorded in the same rat show the occurrence of recurrent activation of expiratory $\mathrm{ABD}_{\mathrm{EMG}}$ activity during $\mathrm{REM}(n=7 ; 42$ of 103 REM epochs longer than $10 \mathrm{~s})$.

spiratory period, with a limited effect on the tidal volume and the abolishment of the state-dependent inspiratory modulation of upper airway muscle.

State-dependent modulation of breathing in natural sleep To determine whether respiratory changes in urethane anesthesia were comparable with what occurs during sleep, seven rats were studied during natural sleep.
Despite the irregular pattern of sleep/wake activity in rats (Zepelin et al., 2005; Fraigne and Orem, 2011), we were able to distinguish, by means of EEG recordings combined with neck $\mathrm{EMG}_{\mathrm{EM}}$ activity, periods of waking $(38.8 \pm 4.6 \%$ of recorded time), $\operatorname{nREM}(47.1 \pm 2.9 \%)$, and REM (13.8 $\pm 3.2 \%)$ sleep (Fig. 6$)$ and to quantify breathing pattern in relation to each state.

During quiet wakefulness, breathing and sigh rate were $115.9 \pm$ 3.2 breaths per minute $(\mathrm{bpm})$ and $39.5 \pm 1.1 \mathrm{sighs} / \mathrm{h}$, respectively. 
$\mathrm{GG}_{\mathrm{EMG}}$ was either tonic or rhythmic and inspiratory-related with interspersed periods of irregular large-amplitude non-respiratoryrelated activity during active behaviors associated with licking and chewing. Similarly, $\mathrm{ABD}_{\mathrm{EMG}}$ activity was associated with whole-body movements (non-respiratory-modulated). Occasionally, some expiratory activity occurred.

During nREM sleep, both breathing and sigh rate decreased to $109.2 \pm 4.5 \mathrm{bpm}$ and $11.9 \pm 2.2$ sighs/h, respectively. Net $\mathrm{GG}_{\mathrm{EMG}}$ activity (which was both rhythmic respiratory-related and nonrespiratory-related) decreased, and $\mathrm{ABD}_{\mathrm{EMG}}$ activity most frequently became tonic.

Within the brief REM epochs $(1.4 \pm 0.1 \mathrm{~min} ; n=7$ rats; 103 epochs) average breathing frequency was $101.7 \pm 2.23 \mathrm{bpm}$, with irregular periods of high frequency and periods of hypopneas, which significantly increased the CV in REM by $62.0 \pm 11.6 \%$ over that recorded during nREM epochs. Sigh rate was higher than in nREM epochs $(22.3 \pm 2.6$ sighs/h, $p=0.004)$. Rats occasionally showed spontaneous apneas ( $3.7 \pm 0.3 \mathrm{~s} ; n=36$ events in seven rats, over $2.35 \mathrm{~h}$ of total REM time) that were distributed exclusively during REM sleep. DIA peak amplitude did not significantly change when transitioning from nREM to REM sleep $\left(1.3 \pm 1.5 \%\right.$ increase in REM compared with nREM state, $t_{(6)}=$ $0.66, p=0.2 ; n=7)$.

Similar to previous data (Megirian et al., 1985; Horner, 2008a), when rhythmic $\mathrm{GG}_{\mathrm{EMG}}$ inspiratory activity was present, we observed a depression during transitions from nREM to REM (Fig. 6A). In addition, tonic non-respiratory-related activity decreased $(28.8 \pm 8.8 \%$ decrease in REM compared with nREM state, $\left.t_{(4)}=2.1, p=0.05 ; n=5\right)$.

When transitioning from nREM to REM, both tonic and expiratory rhythmic $\mathrm{ABD}_{\mathrm{EMG}}$ activity decreased as well $(29.5 \pm 7.0 \%$ decrease in REM compared with nREM state; $t_{(5)}=4.14 ; p=4.3 \times$ $10^{-3} ; n=6$; Fig. $6 A$ ). Interestingly, in several REM epochs ( 42 of 103 REM epochs; $n=7$ ), we observed the sudden rhythmic and expiratory-related activation of $\mathrm{ABD}_{\mathrm{EMG}}$ activity (Fig. $6 \mathrm{~B}$ ). This activity was not associated with awakening, as confirmed by EEG and neck $\mathrm{EMG}_{\text {; }}$ recordings. It was clearly expiratory, in that it was antiphase with concurrently recorded DIA EMG $_{\text {ac- }}$ tivity, and was not associated with non-respiratory phasic REM activity, as confirmed by neck $\mathrm{EMG}_{\mathrm{E}}$ activity. These results suggest that, similar to our data in urethane-anesthetized rats, $\mathrm{ABD}_{\mathrm{EMG}}$ activity is sometimes potentiated during natural REM sleep in rats.

\section{Discussion}

This study demonstrates that brain-state alternations in urethaneanesthetized rats are strongly associated with respiratory changes that closely reproduce those that occur during natural sleep.

\section{State-dependent modulation of respiratory activity}

Urethane anesthesia is commonly used for cardio-respiratory studies attributable to limited effects on cardiovascular, respiratory, and spinal reflexes, and its long-lasting stable sedative level (Maggi and Meli, 1986; Teppema and Baby, 2011). Urethane is a nontypical general anesthetic because it has only moderate effects on excitatory or inhibitory amino acid neurotransmission (Hara and Harris, 2002). Thus, it does not have the GABAergic agonistic profile typical of the majority of anesthetics (Antkowiak, 2001; Thompson and Wafford, 2001; Rudolph and Antkowiak, 2004; Franks, 2006). Instead, it hyperpolarizes cortical neurons by modulating a resting potassium conductance (Sceniak and Maciver, 2006).
Forebrain EEG state is not constant during urethane anesthesia but undergoes alternations that resemble natural sleep (Clement et al., 2008). In this study, we have shown that breathing patterns also fluctuate predictably with changes in forebrain state. Specifically, increases in breathing rate and its variability and in ventilation during REM-like states were similar to changes occurring in REM sleep in humans and rats (Aserinsky and Kleitman, 1953; Aserinsky, 1965; McNamara et al., 2002; Fukumizu and Kohyama, 2004; Qureshi et al., 2009; Fraigne and Orem, 2011).

Another interesting characteristic was the presence of largeamplitude breaths (sighs) that were most common in REM-like and transition states. Sighs are an important reflexive behavior (Bartlett, 1971) that function to prevent alveolar atelectasis, increase pulmonary compliance, and functional residual capacity, all of which are hypothesized to maintain lung volume and minimize the metabolic cost of breathing (Bartlett, 1971; Marshall and Metcalfe, 1988; Orem and Trotter, 1993; Hoch et al., 1998). It is also hypothesized that sighs are important in resetting respiratory and cardiovascular variability (Bartlett, 1971; Kahn et al., 1988; Franco et al., 2003; Baldwin et al., 2004). Importantly, statedependent changes in sigh rate that occur in natural sleep (Hoch et al., 1998; McNamara et al., 2002; Fukumizu and Kohyama, 2004; Qureshi et al., 2009) were similar to those described here under urethane anesthesia.

Studies of REM epochs and underlying mechanisms are extremely challenging in any species but especially in rats in which sleep is highly fragmented, characterized by frequent awakenings and brief, unpredictable REM epochs (Zepelin et al., 2005). An additional difficulty is that experimental manipulations themselves cause state transitions or disrupt sleep entirely. This makes the urethane model particularly appealing because state changes are consistent, long lasting, and predictable. Of course, the stereotyped nature of state alternations and their experimental modifiability under urethane compared with natural sleep highlights that the urethane model is unlikely to replicate all aspects of natural sleep. Nevertheless, it is this predictability and the extended duration of sleep phases that will most significantly enhance mechanistic studies.

REM-like sleep can be artificially induced in anesthetized mammals by microinjecting muscarinic agonists (e.g., carbachol) into the dorsal pontine reticular formation (George et al., 1964), and this manipulation often demonstrates characteristic electrographic REM-like patterns (HPC theta rhythm and ponto-geniculo-occipital waves), inhibition of noradrenergic and serotonergic REM-promoting neurons, and other corresponding physiological variables. Indeed, muscle atonia in upper airway muscles is an important feature of this model (Horner and Kubin, 1999). However, increased respiratory variability, a hallmark of natural REM sleep, does not occur in the carbachol model of REM sleep (Tojima et al., 1992; Horner and Kubin, 1999), and induction of hippocampal activated states may not occur (Horner and Kubin, 1999).

Perhaps the most significant limitation of the carbachol model is that each state transition is dependent on a carbachol injection. Repeatability in the same animal is a significant problem, i.e., the number of transitions induced in the same animal is limited (Kubin, 2001). In contrast, under urethane, state alternations occur spontaneously in a predictable manner for hours, providing ample time for physiological measurements under baseline conditions, during manipulations, and recovery. Importantly, state alternations are remarkably robust to manipulations (Clement et al., 2008; present results). 


\section{State-dependent respiratory muscle modulation during} urethane anesthesia and natural sleep

In urethane-anesthetized rats, muscle atonia is present in $\mathrm{GG}_{\mathrm{EMG}}$, but $\mathrm{DIA}_{\mathrm{EMG}}$ and $\mathrm{INT}_{\mathrm{EMG}}$ change little with brain-state transitions, similar to natural sleep (Sherrey and Megirian, 1977, 1980; Sherrey et al., 1988). In addition, we made the unexpected observation that expiratory $\mathrm{ABD}_{\mathrm{EMG}}$ can emerge during REM-like state and, importantly, that such increases also occur in $\sim 40 \%$ of natural REM epochs.

State-dependent modulation of upper airway muscles, especially the GG, has received particular attention because, in humans, reduced activity in the GG during sleep is a key factor in obstructive sleep apnea (Sauerland and Harper, 1976; Remmers et al., 1978). The magnitude of the depression in $\mathrm{GG}_{\mathrm{EMG}}$ activity during sleep (Jelev et al., 2001; Sood et al., 2005; Horner, 2008a; Lu and Kubin, 2009) depends strongly on posture, vestibular inputs, and state-dependent neuromodulators (Megirian et al., 1985; Rossiter and Yates, 1996; Horner et al., 2002; Horner, 2008b). Our results suggest that urethane anesthesia does not interfere with the neuromodulatory processes controlling GG muscular activity, at the level of either the motoneuron or premotoneuron networks that determine muscle activity. Urethane anesthesia is therefore likely to be a valuable experimental model for these processes given that state changes occur in such a repetitive, predictable, and consistent nature. This will facilitate the analysis of how ventilation changes with state as well as the analysis of cellular, synaptic, and neurochemical mechanisms that underlie both state transitions and state-dependent modulation of respiration.

Although the majority of motoneurons and muscles reduce their activity during REM sleep, ABD expiratory muscles are a clear exception in both natural REM and during REM-like events under urethane anesthesia. Abdominal recruitment in REM-like events was not associated with a change in the depth of anesthesia, blood pressure, or end-expiratory $\mathrm{CO}_{2}$ levels. This excitatory component was clearly expiratory related, but neither its source nor function are known. Abdominal muscles are not generally active at rest but are frequently activated during quiet sleep in healthy humans, in patients with obstructive sleep apnea, and in snorers (Skatrud and Dempsey, 1985; Skatrud et al., 1988). In rats, abdominal expiratory-related activity is induced or potentiated by chemosensory stimulation (Iizuka and Fregosi, 2007; Marina et al., 2010; Abbott et al., 2011), exercise, and selective stimulation of the para-facial respiratory group (Pagliardini et al., 2011) [the proposed expiratory rhythm generator (Mellen et al., 2003; Janczewski and Feldman, 2006)]. Thus, it is possible that $\mathrm{ABD}_{\mathrm{EMG}}$ recruitment during REM-like periods was caused by increased respiratory drive. However, we do not consider this likely because there was no increase in end-expiratory $\mathrm{CO}_{2}$ levels. It will be of interest to study the central correlates of abdominal muscle activation. It is also intriguing to speculate that expiratory-related recruitment helps preserve respiratory function during state-dependent changes in respiratory network excitability.

\section{Chemosensitivity under urethane anesthesia}

Chemosensitivity is generally depressed during sleep (for review, see Douglas, 2005; Kuwaki et al., 2010). Anesthesia also depresses hypoxic or hypercapnic ventilatory responses (Douglas, 2005; Kuwaki et al., 2010; Nattie and Li, 2010). Changes in respiratory chemosensitivity between REM and nREM, however, are less clear. It is proposed that, compared with wakefulness, chemosensitivity is depressed in nREM and further depressed in REM sleep
(Douglas, 2005). However, experimental data are limited because of the brevity of REM epochs in natural sleep and the tendency for chemosensory stimuli (hypoxia or hypercapnia) to cause arousal (Horner et al., 2002; Li and Nattie, 2006, 2010). In our experiments, we observed a stronger hypercapnic ventilatory response in nREM-like compared with REM-like epochs, but these differences were not dramatic. Hypoxic ventilatory responses were similar across states.

Similar to previous results in natural sleep (Megirian et al., 1985; Horner et al., 2002), we observed strong $\mathrm{CO}_{2}$-mediated potentiation of $\mathrm{GG}_{\mathrm{EMG}}$ activity in nREM-like epochs, but limited effects during REM-like epochs, suggesting that EMG potentiation is still present under urethane anesthesia and is still state dependent. $\mathrm{ABD}_{\mathrm{EMG}}$ activity was also potentiated during $\mathrm{CO}_{2}$ stimulation, consistent with previous reports (Iizuka and Fregosi, 2007; Marina et al., 2010; Abbott et al., 2011).

Mild hypoxia potently increased respiratory frequency across states and decreased the time spent in nREM-like sleep, similar to natural sleep (Pappenheimer, 1977; Horner et al., 2002). Relative differences among states were maintained (higher respiratory and sigh rates, tidal volume, minute ventilation in REM-like state). Interestingly, prolonged hypoxia depressed $\mathrm{GG}_{\mathrm{EMG}}$ statedependent modulation. The lack of hypoxia-evoked potentiation of $\mathrm{GG}_{\mathrm{EMG}}$ activity may reflect that our manipulation was a relatively mild stimulus. However, this does not explain the loss of inspiratory modulation across states, which may reflect the reduction of nREM epoch duration in which inspiratory modulation of $\mathrm{GG}_{\mathrm{EMG}}$ develops gradually. It is also possible that urethane suppresses hypoxia-induced potentiation of $\mathrm{GG}_{\mathrm{EMG}}$ activity (Cao and Ling, 2010).

Although manipulating respiratory drive with hypercapnia and hypoxia did not abolish brain-state alternations, this procedure did alter brain-state dynamics. Both stimuli altered the total nREM-like to REM-like cycle periods and shifted the relative time spent in each state; hypercapnia favored nREM-like state, whereas mild hypoxia shifted the balance toward REM-like state. This, together with previous work regarding effects of ambient temperature (Whitten et al., 2009), suggests that the control of forebrain state is susceptible to physiologically relevant metabolic signals.

Notwithstanding the general effects of anesthesia on respiration, here we provide substantial evidence that, in urethaneanesthetized rats, state-dependent changes in respiration closely resemble those occurring in natural sleep. This predictable model of sleep state has the potential to provide the foundation for mechanistic studies of respiratory control during sleep and ultimately a means for assessing the efficacy of pharmacological interventions.

\section{References}

Abbott SB, Stornetta RL, Coates MB, Guyenet PG (2011) Phox2bexpressing neurons of the parafacial region regulate breathing rate, inspiration, and expiration in conscious rats. J Neurosci 31:16410-16422.

Antkowiak B (2001) How do general anaesthetics work? Naturwissenschaften 88:201-213.

Aserinsky E (1965) Periodic respiratory pattern occurring in conjunction with eye movements during sleep. Science 150:763-766.

Aserinsky E, Kleitman N (1953) Regularly occurring periods of eye motility, and concomitant phenomena, during sleep. Science 118:273-274.

Baldwin DN, Suki B, Pillow JJ, Roiha HL, Minocchieri S, Frey U (2004) Effect of sighs on breathing memory and dynamics in healthy infants. J Appl Physiol 97:1830-1839.

Bartlett D Jr (1971) Origin and regulation of spontaneous deep breaths. Respir Physiol 12:230-238. 
Cao Y, Ling L (2010) Urethane inhibits genioglossal long-term facilitation in un-paralyzed anesthetized rats. Neurosci Lett 477:124-128.

Carskadon MA, Dement WC (2005) Normal human sleep: an overview. In: Principles and practice of sleep medicine, Ed 4, pp 13-23. Philadelphia: Elsevier/Saunders.

Chase MH, Morales FR (2005) Control of motoneurons during sleep. In: Principles and practice of sleep medicine. Philadelphia: Elsevier/Saunders.

Clement EA, Richard A, Thwaites M, Ailon J, Peters S, Dickson CT (2008) Cyclic and sleep-like spontaneous alternations of brain state under urethane anaesthesia. PLoS One 3:e2004.

Douglas NJ (2005) Respiratory physiology: control of ventilation. In: Principles and practice of sleep medicine, Ed 4, pp 224-231. Philadelphia: Elsevier/Saunders.

Fraigne JJ, Orem JM (2011) Phasic motor activity of respiratory and nonrespiratory muscles in REM sleep. Sleep 34:425-434.

Franco P, Verheulpen D, Valente F, Kelmanson I, de Broca A, Scaillet S, Groswasser J, Kahn A (2003) Autonomic responses to sighs in healthy infants and in victims of sudden infant death. Sleep Med 4:569-577.

Franks NP (2006) Molecular targets underlying general anaesthesia. Br J Pharmacol 147 [Suppl 1]:S72-S81.

Fukumizu M, Kohyama J (2004) Central respiratory pauses, sighs, and gross body movements during sleep in children. Physiol Behav 82:721-726.

Galland BC, Taylor BJ, Bolton DP, Sayers RM (2000) Vasoconstriction following spontaneous sighs and head-up tilts in infants sleeping prone and supine. Early Hum Dev 58:119-132.

George R, Haslett WL, Jenden DJ (1964) A cholinergic mechanism in the brainstem reticular formation: induction of paradoxical sleep. Int J Neuropharmacol 3:541-552.

Grahn DA, Heller HC (1989) Activity of most rostral ventromedial medulla neurons reflect EEG/EMG pattern changes. Am J Physiol 257:R1496-R1505.

Hara K, Harris RA (2002) The anesthetic mechanism of urethane: the effects on neurotransmitter-gated ion channels. Anesth Analg 94:313-318, table of contents.

Hoch B, Bernhard M, Hinsch A (1998) Different patterns of sighs in neonates and young infants. Biol Neonate 74:16-21.

Horner RL (2008a) Neuromodulation of hypoglossal motoneurons during sleep. Respir Physiol Neurobiol 164:179-196.

Horner RL (2008b) Control of genioglossus muscle by sleep statedependent neuromodulators. Adv Exp Med Biol 605:262-267.

Horner RL, Kubin L (1999) Pontine carbachol elicits multiple rapid eye movement sleep-like neural events in urethane-anaesthetized rats. Neuroscience 93:215-226.

Horner RL, Liu X, Gill H, Nolan P, Liu H, Sood S (2002) Effects of sleepwake state on the genioglossus vs. diaphragm muscle response to $\mathrm{CO}(2)$ in rats. J Appl Physiol 92:878-887.

Hunter JD, Milsom WK (1998) Cortical activation states in sleep and anesthesia. I: Cardio-respiratory effects. Respir Physiol 112:71-81.

Hunter JD, McLeod JZ, Milsom WK (1998) Cortical activation states in sleep and anesthesia. II: Respiratory reflexes. Respir Physiol 112:83-94.

Iizuka M, Fregosi RF (2007) Influence of hypercapnic acidosis and hypoxia on abdominal expiratory nerve activity in the rat. Respir Physiol Neurobiol 157:196-205

Janczewski WA, Feldman JL (2006) Distinct rhythm generators for inspiration and expiration in the juvenile rat. J Physiol 570:407-420.

Jelev A, Sood S, Liu H, Nolan P, Horner RL (2001) Microdialysis perfusion of 5-HT into hypoglossal motor nucleus differentially modulates genioglossus activity across natural sleep-wake states in rats. J Physiol 532: 467-481.

Kahn A, Blum D, Rebuffat E, Sottiaux M, Levitt J, Bochner A, Alexander M, Grosswasser J, Muller MF (1988) Polysomnographic studies of infants who subsequently died of sudden infant death syndrome. Pediatrics 82:721-727.

Krenzer M, Anaclet C, Vetrivelan R, Wang N, Vong L, Lowell BB, Fuller PM, Lu J (2011) Brainstem and spinal cord circuitry regulating REM sleep and muscle atonia. PLoS One 6:e24998.

Krieger J (2005) Respiratory physiology: breathing in normal subjects. In: Principles and practice of sleep medicine, Ed 4, pp 232-244. Philadelphia: Elsevier/Saunders.

Krimsky WR, Leiter JC (2005) Physiology of breathing and respiratory control during sleep. Semin Respir Crit Care Med 26:5-12.
Kubin L (2001) Carbachol models of REM sleep: recent developments and new directions. Arch Ital Biol 139:147-168.

Kuwaki T, Li A, Nattie E (2010) State-dependent central chemoreception: a role of orexin. Respir Physiol Neurobiol 173:223-229.

Li A, Nattie E (2006) Catecholamine neurones in rats modulate sleep, breathing, central chemoreception and breathing variability. J Physiol 570:385-396.

Li A, Nattie E (2010) Antagonism of rat orexin receptors by almorexant attenuates central chemoreception in wakefulness in the active period of the diurnal cycle. J Physiol 588:2935-2944.

Lu JW, Kubin L (2009) Electromyographic activity at the base and tip of the tongue across sleep-wake states in rats. Respir Physiol Neurobiol 167:307-315

Maggi CA, Meli A (1986) Suitability of urethane anesthesia for physiopharmacological investigations in various systems. Part 2: Cardiovascular system. Experientia 42:292-297.

Marina N, Abdala AP, Trapp S, Li A, Nattie EE, Hewinson J, Smith JC, Paton JF, Gourine AV (2010) Essential role of Phox2b-expressing ventrolateral brainstem neurons in the chemosensory control of inspiration and expiration. J Neurosci 30:12466-12473.

Marshall JM, Metcalfe JD (1988) Cardiovascular changes associated with augmented breaths in normoxia and hypoxia in the rat. J Physiol 400:15-27.

McNamara F, Lijowska AS, Thach BT (2002) Spontaneous arousal activity in infants during NREM and REM sleep. J Physiol 538:263-269.

Megirian D, Hinrichsen CF, Sherrey JH (1985) Respiratory roles of genioglossus, sternothyroid, and sternohyoid muscles during sleep. Exp Neurol 90:118-128.

Mellen NM, Janczewski WA, Bocchiaro CM, Feldman JL (2003) Opioidinduced quantal slowing reveals dual networks for respiratory rhythm generation. Neuron 37:821-826.

Morales FR, Boxer P, Chase MH (1987) Behavioral state-specific inhibitory postsynaptic potentials impinge on cat lumbar motoneurons during active sleep. Exp Neurol 98:418-435

Murakami M, Kashiwadani H, Kirino Y, Mori K (2005) State-dependent sensory gating in olfactory cortex. Neuron 46:285-296.

Nattie E, Li A (2010) Central chemoreception in wakefulness and sleep: evidence for a distributed network and a role for orexin. J Appl Physiol 108:1417-1424.

Orem J, Trotter RH (1993) Medullary respiratory neuronal activity during augmented breaths in intact unanesthetized cats. J Appl Physiol 74:761-769.

Pagliardini S, Janczewski WA, Tan W, Dickson CT, Deisseroth K, Feldman JL (2011) Active expiration induced by excitation of ventral medulla in adult anesthetized rats. J Neurosci 31:2895-2905.

Pappenheimer JR (1977) Sleep and respiration of rats during hypoxia. J Physiol 266:191-207.

Parmeggiani PL (1978) Regulation of the activity of respiratory muscles during sleep. Adv Exp Med Biol 99:47-57.

Qureshi M, Khalil M, Kwiatkowski K, Alvaro RE (2009) Morphology of sighs and their role in the control of breathing in preterm infants, term infants and adults. Neonatology 96:43-49.

Remmers JE, deGroot WJ, Sauerland EK, Anch AM (1978) Pathogenesis of upper airway occlusion during sleep. J Appl Physiol 44:931-938.

Rossiter CD, Yates BJ (1996) Vestibular influences on hypoglossal nerve activity in the cat. Neurosci Lett 211:25-28.

Rudolph U, Antkowiak B (2004) Molecular and neuronal substrates for general anaesthetics. Nat Rev Neurosci 5:709-720.

Sauerland EK, Harper RM (1976) The human tongue during sleep: electromyographic activity of the genioglossus muscle. Exp Neurol 51:160-170.

Sceniak MP, Maciver MB (2006) Cellular actions of urethane on rat visual cortical neurons in vitro. J Neurophysiol 95:3865-3874.

Sherrey JH, Megirian D (1977) State dependence of upper airway respiratory motoneurons: functions of the cricothyroid and nasolabial muscles of the unanesthetized rat. Electroencephalogr Clin Neurophysiol 43:218-228.

Sherrey JH, Megirian D (1980) Respiratory EMG activity of the posterior cricoarytenoid, cricothyroid and diaphragm muscles during sleep. Respir Physiol 39:355-365.

Sherrey JH, Pollard MJ, Megirian D (1988) Proprioceptive, chemoreceptive and sleep state modulation of expiratory muscle activity in the rat. Exp Neurol 101:50-62. 
Sieck GC, Trelease RB, Harper RM (1984) Sleep influences on diaphragmatic motor unit discharge. Exp Neurol 85:316-335.

Skatrud JB, Dempsey JA (1985) Airway resistance and respiratory muscle function in snorers during NREM sleep. J Appl Physiol 59:328-335.

Skatrud JB, Dempsey JA, Badr S, Begle RL (1988) Effect of airway impedance on $\mathrm{CO} 2$ retention and respiratory muscle activity during NREM sleep. J Appl Physiol 65:1676-1685.

Soja PJ, Morales FR, Baranyi A, Chase MH (1987) Effect of inhibitory amino acid antagonists on IPSPs induced in lumbar motoneurons upon stimulation of the nucleus reticularis gigantocellularis during active sleep. Brain Res 423:353-358.

Sood S, Morrison JL, Liu H, Horner RL (2005) Role of endogenous serotonin in modulating genioglossus muscle activity in awake and sleeping rats. Am J Respir Crit Care Med 172:1338-1347.

Teppema LJ, Baby S (2011) Anesthetics and control of breathing. Respir Physiol Neurobiol 177:80-92.
Thompson SA, Wafford K (2001) Mechanism of action of general anaesthetics-new information from molecular pharmacology. Curr Opin Pharmacol 1:78-83.

Tojima H, Kubin L, Kimura H, Davies RO (1992) Spontaneous ventilation and respiratory motor output during carbachol-induced atonia of REM sleep in the decerebrate cat. Sleep 15:404-414.

Whitten TA, Martz LJ, Guico A, Gervais N, Dickson CT (2009) Heat synch: inter- and independence of body-temperature fluctuations and brainstate alternations in urethane-anesthetized rats. J Neurophysiol 102: 1647-1656.

Wolansky T, Clement EA, Peters SR, Palczak MA, Dickson CT (2006) Hippocampal slow oscillation: a novel EEG state and its coordination with ongoing neocortical activity. J Neurosci 26:6213-6229.

Zepelin H, Siegel JM, Tobler I (2005) Mammalian sleep. In: Principles and practice of sleep medicine, Ed 4, pp 91-100. Philadelphia: Elsevier/Saunders. 